\title{
Las representaciones de la identidad del estudiante: perspectivas de dos comunidades lingüístico-culturales
}

Representations of Students' Identity:

Perspectives from Two Linguistic and Cultural Communities

As representações da identidade do estudante:

perspectivas de duas comunidades

linguístico-culturais

\section{Óscar Torres Rubiano* iD orcid.org/0000-0003-1298-0125}

\section{(c) $\underset{\mathrm{BY}}{\mathrm{N}} \underset{\mathrm{Nc}}{\mathrm{a}}$}

Recibido: 24/01/2018

Evaluado: 06/08/2018

Estudiante del doctorado en Ciencias del Lenguaje, Universidad de Nantes, docente Universidad de Nantes, 


\section{Resumen}

Nuestro interés surge de la reflexión sobre las dificultades que los estudiantes viven cuando se vinculan a instituciones universitarias en el extranjero durante un programa de intercambio. Consideramos que esta problemática se puede explorar a partir del estudio lingüístico-discursivo de las representaciones identitarias del estudiante en términos de su quehacer, de sus cualidades y de su relación con el entorno. Para ello, nos propusimos como objetivo analizar y comparar las representaciones del término estudiante en dos comunidades lingüístico-culturales diversas de estudiantes que se forman como futuros docentes de lenguas extranjeras: la primera, conformada por 25 estudiantes colombianos, y la segunda, por 25 estudiantes franceses. El estudio demuestra que tanto los participantes colombianos como los franceses construyen dos representaciones antinómicas del término estudiante. Una corresponde a un sujeto pasivo, y se asocia a la obligación institucional de aprender. La otra se construye alrededor de la idea de actor-ciudadano, y se asocia a la voluntad de poner al servicio de la comunidad las competencias y saberes adquiridos por el estudiante. Estas conclusiones nos conducen a reflexionar sobre el rol de los intercambios académicos. Consideramos que estos se podrían aprovechar como un escenario en donde se desarrollan competencias ciudadanas e interculturales a través de la interpretación de las nuevas realidades locales que integran los estudiantes en intercambio.

\section{Palabras clave}

Identidad profesional; estudiantes extranjeros; semántica; comprensión cultural; comunicación intercultural

\section{Keywords}

professional identity; foreign students; semantics; cultural awareness; intercultural communication

\begin{abstract}
Our research interest stems from the difficulties that students participating in exchange programmes can experience when they study abroad. We believe that this issue can be explored from a linguistic and discursive study of the representations of the student's identity in terms of actions, qualities and his/her relationship with the environment. The purpose of our study is to analyze and compare the representations of the word student in two different linguistic and cultural communities who are studying to become foreign-language teachers, 25 of whom are Colombian and 25 are French. Our study shows that both French and Colombian participants propose two antithetical representations for the term student. The first one is a passive subject who is obliged to learn by academic institutions. The second one associates the student to the idea of an actor-citizen willing to put his/her knowledge and competences to the service of his/her community. These conclusions lead us to reflect about the role of academic exchanges. We believe that they could be a scenario to develop citizenship and intercultural competences thanks to the students' interpretation of the new local realities.
\end{abstract}

\section{Resumo}

Nosso interesse surge da reflexão sobre as dificuldades que os estudantes exprimem ao se vincular a instituições universitárias no exterior durante um programa de intercâmbio. Consideramos que esta problemática pode ser explorada a partir do estudo linguístico-discursivo das representações do termo estudante em duas comunidades linguístico-culturais diversas de estudantes em formação docente de línguas estrangeiras: a primeira está conformada por 25 estudantes colombianos e a segunda, por 25 estudantes franceses. $O$ estudo assinala que tanto os participantes colombianos quanto os franceses constituem duas representações antinômicas do termo estudante. Uma corresponde ao sujeito passivo e é associada à obrigação institucional de aprender. A outra está construída ao redor da ideia de ator-cidadão e está associada à vontade de oferecer as competências e conhecimentos adquiridos pelo estudante ao serviço da comunidade. Essas conclusões nos levam a refletir sobre o papel dos intercâmbios acadêmicos. Acreditamos que esse poderiam ser aproveitados como um canário onde as competências cidadãs

N. ${ }^{\circ} 77$ e interculturais são desenvolvidas através da interpretação das novas realidades locais das que participam esses estudantes.

\section{Palavras-chave}

identidade profissional; estudantes estrangeiros; semântica; compreensão cultural; comunicação intercultura 
La Maestría en Enseñanza de Lenguas Extranjeras de la Universidad Pedagógica Nacional ha sido el escenario de múltiples intercambios humanos, pedagógicos y científicos con otras instituciones universitarias nacionales e internacionales. Una prueba de ello es la alianza con la Universidad de Nantes y el Instituto de Investigación y de Formación en Francés como Lengua Extranjera (IRFFLE, por sus siglas en francés) que ha brindado la oportunidad a alumnos colombianos y franceses de realizar una parte de su formación a uno y otro lado del Atlántico. Estos intercambios han enriquecido los horizontes de los estudiantes, quienes descubren e intentan adaptarse a un nuevo ámbito universitario e institucional.

Sin embargo, dicha adaptación está acompañada de múltiples dificultades y cuestionamientos por parte del estudiante, quien debe intentar comprender las prácticas y rituales de la institución educativa que lo acoge. Estos están mediados por las representaciones culturales y las normas institucionales del país y de la sociedad en donde se sitúa la universidad. Durante este proceso de integración, los estudiantes cuestionan las representaciones ya adquiridas en sus países e instituciones de origen en cuanto a lo que debe ser la enseñanza y el aprendizaje, y por consiguiente, lo que se espera del docente y del estudiante en este ámbito institucional.

Desde nuestra experiencia en la Universidad Pedagógica Nacional y en la Universidad de Nantes hemos podido recolectar múltiples testimonios de estudiantes en intercambio respecto a su adaptación cultural e institucional. Sus palabras comprueban que integrar un nuevo universo institucional provoca una desestabilización de los referentes culturales ya adquiridos sobre lo que significa aprender y enseñar en la universidad.

Por ejemplo, los estudiantes colombianos que participan en intercambios académicos en Francia se sorprenden al verse enfrentados con prácticas educativas que se fundamentan en clases magistrales (cours magistraux). Esta forma de enseñanza se centra en el profesor, quien dicta contenidos teóricos; algunas veces se realizan breves intercambios entre este y el alumno al final del curso. Los estudiantes colombianos, cuyas representaciones de la enseñanza están fuertemente constituidas por perspectivas constructivistas estudiadas durante la licenciatura en la Universidad Pedagógica, juzgan dicha práctica como tradicionalista. Además, se ven enfrentados a un cambio radical en cuanto a las formas de evaluación, puesto que en el país galo es frecuente que haya un único examen al final del semestre. Esta modalidad evaluativa, ampliamente difundida en el ámbito universitario francés, es antinómica a las representaciones de los alumnos colombianos, que generalmente asocian la evaluación a la idea de proceso y no de resultado. 
De igual manera, los estudiantes franceses se enfrentan en las aulas colombianas con nuevas prácticas de enseñanza y aprendizaje que difieren de sus modelos de referencia. Es el caso de algunos espacios académicos en los que estudiantes y docentes construyen sus conocimientos a partir del debate de ideas. Esta práctica de enseñanza, en la que el rol del docente se limita al de mediador, puede ser percibida por los alumnos franceses como una falta de rigurosidad del maestro, quien no asume su rol de autoridad del conocimiento. Suponemos que dicha representación ha sido transmitida e interiorizada a través de distintas instituciones educativas y administrativas de dicho país. Allí se espera que el profesor asuma primordialmente su rol de especialista definiendo e ilustrando conceptos que los estudiantes deberán reproducir y analizar en el examen final' ${ }^{1}$.

Estos testimonios sobre las dificultades vividas por los alumnos que parten en intercambio a otros países nos han llevado a indagarnos sobre las representaciones identitarias que el estudiante construye sobre sí mismo a lo largo de su vida académica. Consideramos que su estudio constituye un esfuerzo hacia el reconocimiento y la aceptación de la diversidad de modelos de aprendizaje-enseñanza en las instituciones universitarias. Fruto de esta reflexión, profesores y estudiantes podrían poner en marcha estrategias conjuntas que no busquen la simple asimilación cultural y académica del estudiante de intercambio, sino que tiendan hacia la construcción de un diálogo intercultural entre distintas tradiciones universitarias.

El estudio que presentamos a continuación es el resultado de una investigación realizada en el marco de la formación en Maestría en Enseñanza de Lenguas Extranjeras². Nuestro objetivo es analizar las representaciones lingüísticas y discursivas del término estudiante ${ }^{3}$, así como su movilización de valores sociales desde una perspectiva identitaria. Para ello, compararemos las representaciones discursivas de futuros docentes de lenguas extranjeras de dos instituciones: la Universidad Pedagógica Nacional (Colombia) y la Universidad de Toulouse Le Mirail (Francia). Como se observa, nuestros dos grupos de participantes se diferencian por

1 Con esto no se quiere decir que el debate de ideas no exista en las aulas francesas, sino que las expectativas del rol del docente son diferentes. En Francia, el papel del profesor universitario está más asociado a su rol como especialista del área de conocimiento que enseña que a sus competencias pedagógicas. Por ende, el estudiante francés espera que el profesor encarne su autoridad de especialista y de transmisor de conocimientos. Una prueba de ello son los contenidos de los concursos nacionales para acceder a la profesión docente, que se enfocan en evaluar si el candidato es especialista en un área de conocimiento.

2 En este artículo presentamos una parte de nuestro trabajo de grado. Originalmente el estudio analiza las representaciones identitarias del estudiante y del profesor a partir de las representaciones discursivas propuestas por estudiantes colombianos, franceses e ingleses.

3 El termino estudiante aparecerá en cursiva para hacer referencia, de forma exclusiva, a nuestro objeto de estudio. 
pertenecer a horizontes lingüísticos, culturales e institucionales distintos y se asemejan en cuanto a que siguen una formación para diplomarse como docentes de lenguas extranjeras. Esta comparación respecto a las representaciones del estudiante en el discurso nos ayudará a determinar cómo se podría construir un diálogo intercultural inclusivo de las prácticas educativas; en nuestro caso, partiendo de dos tradiciones universitarias: la francesa y la colombiana.

\section{Los conceptos de identidad e identidad profesional}

Vale la pena subrayar que buscamos dar cuenta de las representaciones del estudiante desde su identidad profesional. Nuestra perspectiva no solo pretende estudiar las representaciones de las prácticas asociadas a este actor de la educación, en nuestro caso aprender, sino también hacer emerger los imaginarios en torno a los roles que se supone que el estudiante debe cumplir dentro del acto educativo. Visto que nuestro objeto de estudio se construye alrededor de los conceptos de identidad y discurso, consideramos necesario presentar nuestra postura respecto a la relación entre estas dos nociones.

\section{Concepto de identidad}

La identidad es un proceso cognitivo, individual y social, que permite al sujeto darse cuenta de su propia existencia y tomar conciencia de sí mismo. Para que estos procesos se produzcan, el individuo debe percibirse diferente del Otro, de esta manera nace su conciencia identitaria. La identidad se construye, entonces, a partir de un sistema de alteridad basado en un doble proceso de reconocimiento y diferenciación (Dervin, 2008). Un conjunto de individuos puede identificarse como miembros de uno o varios grupos puesto que creen compartir ciertas características, valores o representaciones que los cohesionan como colectividad. Igualmente, una comunidad puede identificarse o sentirse diferente de otras en la medida en que sus miembros sienten atracción cuando perciben al Otro como portador de una diferencia que enriquece al grupo, o rechazo, cuando lo ven como una amenaza. La identidad se construye entonces con base en una suerte de juego dialéctico, en el cual intervienen procesos de reconocimiento y diferenciación de la Alteridad (Charaudeau, 2001).

La identidad se construye esencialmente en tres niveles: el del saber (conocimientos del mundo), el de los juicios (asociado a las creencias) y el de las acciones (asociado al hacer). Estos tres elementos constituyen una red conceptual compleja en la que se interpretan los individuos y las 
comunidades. La superposición de varias redes dentro de una comunidad configura una especie de universo conceptual y de creencias que asegura la comprensión y producción del sentido colectivo (Charaudeau, 2001).

Sin embargo, no podemos limitarnos a definir la identidad en términos de configuración de redes de sentido, puesto que nuestro objetivo es acceder a ellas para interpretarlas. De acuerdo con Ricœur (1985), la identidad se define también como una construcción narrativa, donde el sujeto pensante reconstruye lo que piensa que él es. Puesto que la identidad es una construcción permanente que se realiza a lo largo de la existencia del individuo, la narración vendría siendo una negociación entre una parte estable y otra que se actualiza gracias a las experiencias de vida del sujeto. Es decir, la identidad de un individuo o de un grupo se construye a lo largo de su existencia, pero hay una imagen o representación identitaria que se estabiliza por medio del discurso; es esa fijación discursiva de la identidad que el investigador analiza. En nuestro estudio la estabilización identitaria se provoca cuando se pide a los informantes que definan el término estudiante.

La identidad se puede definir entonces como una construcción mental y discursiva de sí y del Otro que se realiza dentro de un contexto situacional y cognitivo precisos y que tiene en cuenta los tipos de relaciones que tejen los individuos entre sí. En el plano lingüístico esta construcción se realiza gracias a operaciones de designación, de denominación, de definición y también por medio de enunciados tipificantes (Anscombre, 2001) y discriminatorios (Galatanu, 2009). En otras palabras, la identidad es una construcción discursiva que depende del contexto y del rol en el que se sitúa el sujeto-hablante; esta toma de conciencia determina la perspectiva desde la que el sujeto va a reconstruir su identidad en el discurso. Por lo tanto, el trabajo del investigador no consiste en evaluar la veracidad de los enunciados; su análisis debe centrarse en el estudio de los valores sociales que movilizan las representaciones construidas por el discurso.

Hasta aquí hemos dicho que la identidad es una construcción dialéctica entre el reconocimiento y la diferenciación del Otro, que se estructura a través de una red de representaciones de saberes, creencias y prácticas sociales que aseguran la producción del sentido colectivo. También hemos subrayado que el acceso a las representaciones identitarias se realiza únicamente por vía discursiva, lo que produce una fijación momentánea de la identidad. Esta imagen se construye a partir de una toma de posición del sujeto-enunciador en el discurso y depende del contexto en el que él se sitúa. No obstante, la identidad que pretendemos estudiar es de una naturaleza específica, pues analizaremos la identidad profesional de un actor de la educación, o sea la del estudiante. 


\section{La identidad profesional}

Desde la perspectiva ergonómica que adoptamos (Galatanu, 2000a), el estudio de la identidad profesional no se realiza a partir de la observación de una práctica o de una actividad profesional, como ocurre en otras disciplinas (en nuestro caso esto equivaldría a la observación del proceso de aprendizaje del estudiante). Nuestro objeto de estudio estaría constituido, más bien, por categorías de verbalización, provocadas por el investigador, respecto a las actividades o tareas profesionales que un individuo ejecuta durante el ejercicio de su práctica profesional, en nuestro caso aprender. Es decir, en vez de concentrarnos en el análisis de las múltiples tareas que constituyen una profesión, optamos por estudiar las construcciones de sentido y de significado que los profesionales dan a la manera en que realizan su labor. Lo que es realmente significativo no es la acción en sí misma, sino los significados que los actores le dan, por ende, la identidad profesional se abarca como una problemática de comprensión y no de acción (Barbier \& Galatanu, 2004).

Puesto que la identidad, en particular la identidad profesional, es una construcción que se realiza por y en el discurso, adoptamos la perspectiva teórica de la semántica de los posibles argumentativos, que se presenta como una vía de acceso a las representaciones de los sujetos hablantes y a sus identidades. De acuerdo con esta teoría, el discurso permitiría penetrar en las imágenes de Sí y del Otro creadas por cualquier instancia enunciativa. El discurso es, entonces, la vía de acceso a las representaciones y a la evaluación del mundo que se realiza dentro de estos discursos identitarios. A continuación, presentamos los principios teórico-metodológicos que resultan no solo de nuestra posición teórica, sino también de nuestra definición de identidad profesional.

\section{Perspectiva teórico-metodológica}

Visto que nuestro objetivo es comprender y analizar las diferencias y similitudes de la construcción identitaria del estudiante en dos comunidades lingüístico-culturales distintas, hemos decidido adoptar el enfoque de la semántica de posibles argumentativos (en adelante, SPA). Este modelo teórico-metodológico permite dar cuenta del mundo percibido y realizado por la lengua y del potencial discursivo de una palabra, en nuestro caso estudiante, en los discursos.

La SPA ayuda a comprender nuestro objeto de estudio en una interface que cruza los componentes lingüístico, discursivo y cultural, incluyendo la inscripción de lo cultural en las palabras. Por un lado, este modelo se basa en la idea de que el significado de las palabras es compartido por los 
(inter)locutores de una comunidad lingüística, lo que presupone que sus discursos permiten el acceso a la manera en que una colectividad construye la realidad. Por otro lado, este modelo concibe que el sujeto no se limita a describir el mundo o a narrar lo que acontece, sino que se evalúa a sí mismo, al mundo y al Otro. En otras palabras, debido a su implicación en la comunicación el sujeto vehiculiza juicios a través de las entidades léxicas que utiliza en su discurso. En este sentido, la SPA es "una teoría semántica que da cuenta del nivel de inscripción del valor axiológico en el significado de las palabras" (Galatanu, 2000b).

La SPA propone una teorización del significado léxico a partir de un modelo constituido por dos niveles. El primero compuesto de tres estratos: el núcleo (N), los estereotipos (sts) y los posibles argumentativos (PA); y el segundo, constituido por una forma de manifestación discursiva: los despliegues argumentativos (DA) ${ }^{4}$.

En este artículo expondremos exclusivamente el estudio que realizamos del núcleo del término estudiante en español y en francés. Consideramos que el núcleo, que corresponde a los rasgos estables y esenciales del significado de una palabra (Galatanu 2009), permite acceder a las propiedades esenciales y los valores axiológicos que son cristalizados y ampliamente compartidos por una comunidad lingüística y cultural, y dar cuenta de ellos.

De acuerdo con los preceptos metodológicos de la SPA y nuestro objetivo de análisis, el núcleo de la entidad estudiante se estudiará a partir de dos tipos de corpus:

» Las definiciones del término estudiante obtenidas en diccionarios de español y francés.

» Las definiciones de la entidad estudiante brindadas por nuestros informantes colombianos y franceses.

El estudio de este corpus se efectuará en tres fases, así:

» Primera fase. Presentaremos la construcción del significado léxico de la entidad estudiante en español y en francés a partir de diccionarios y las compararemos. Esta construcción del significado da la posibilidad de establecer el núcleo de la entidad léxica objeto de estudio para cada lengua, teniendo como referente nuestro corpus lexicográfico. En nuestro caso, diccionarios de lengua española (Diccionario de la lengua española de la Real Academia Española [DRAE], Diccionario de uso del español de María Moliner y Diccionario del español actual de Manuel Seco) y de lengua francesa (Le Petit Robert 2011, Larousse Le Lexis 2014 Le nouveau Littré 2007

4 Remitimos a los lectores que deseen conocer en detalle este modelo de teorización del significado léxico a los textos aquí referenciados de Galatanu. 
y el Trésor de la Langue Française (en línea), debido a la naturaleza de nuestro estudio, que busca comparar la forma en que dos comunidades lingüístico-culturales construyen la representación identitaria del estudiante.

» Segunda fase. Daremos cuenta de la movilización discursiva que hacen los informantes colombianos y franceses cuando definen el término estudiante. Observaremos que los participantes definieron esta profesión en términos de su inscripción institucional, de sus cualidades y de sus actividades profesionales. El corpus está compuesto por las respuestas de los informantes a tres secciones del cuestionario administrado, cuyo objetivo es conocer sus representaciones del término en cuestión. Esta parte del cuestionario se diseñó con el fin de identificar en el discurso de los informantes los elementos estables del significado léxico de la entidad de estudio, así como la orientación axiológica de las ocurrencias propuestas por los participantes colombianos y franceses.

» Tercera fase. Finalmente se comparará el núcleo construido a partir de las definiciones lexicográficas con las definiciones del término estudiante proporcionadas por nuestros participantes. Ello nos permitirá evaluar el cinetismo ${ }^{5}$ del significado del término de estudio gracias a la comparación entre la construcción del significado de los locutores (parte evolutiva del significado) y las definiciones de los diccionarios (parte estable). Los resultados obtenidos a partir de esta comparación nos darán pistas para determinar los elementos que pueden constituir un diálogo intercultural entre las dos tradiciones universitarias de nuestros informantes.

\section{Los cuestionarios}

Para constituir el corpus de nuestra investigación procedimos a la aplicación de un cuestionario que busca conocer las representaciones discursivas de un grupo de alumnos colombianos y franceses sobre el término estudiante. Este instrumento se concibió a partir de los postulados teóricos de la SPA y los preceptos metodológicos presentados para el estudio de la identidad profesional señalados por Barbier (2006), y se aplicó en la lengua materna de cada uno de los participantes.

El cuestionario se elaboró con el propósito de identificar los elementos estables del significado léxico (núcleo), los elementos que constituyen los bloques argumentativos abiertos (estereotipos) y la orientación axiológica

5 Hace referencia a la transformación del significado léxico y su reconstrucción continua a través de mecanismos en la actuación discursiva de una comunidad discursiva (Galatanu, 2007). 
presente en las ocurrencias propuestas por los participantes de esta investigación. Como lo mencionamos, nos limitaremos a presentar la construcción de la parte estable del significado del término estudiante propuesta por nuestros informantes. De igual modo, analizaremos las representaciones de nuestros informantes en torno a las actividades que el estudiante realiza en su quehacer académico.

Para ello expondremos y analizaremos las respuestas dadas por los encuestados a dos partes del cuestionario. En la primera se interroga a los participantes sobre la manera en que la sociedad definiría el concepto un verdadero estudiante. Esta pregunta se construye a partir de dos estrategias. Por un lado, utilizamos una denominación de representación colectiva: la sociedad. El uso de una fórmula que hace referencia a la idea de expresión pública motiva al informante a presentar de manera más espontánea sus representaciones privadas, puesto que no siente que habla a título personal (Zavalloni, 1998). Por otro lado, la expresión un verdadero constituye un dispositivo discursivo que busca reforzar el potencial axiológico positivo del término estudiante; ello se traduciría en la evocación de valores sociales. En la segunda sección se pide al participante que defina el término estudiante a partir de sus experiencias personales. Esta instrucción busca que el encuestado active su memoria. Dado que todos nuestros participantes han acumulado un vasto número de experiencias, suponemos que sus respuestas constituyen la estabilización de ciertas representaciones que han sido forjadas por las instituciones escolares que los han formado.

\section{Población}

El objetivo de nuestro estudio es analizar y comparar la construcción lingüística y discursiva de las representaciones identitarias del estudiante en dos grupos de alumnos pertenecientes a dos comunidades lingüísticas, culturales e institucionales. El primero, compuesto por 25 estudiantes colombianos que cursan primer semestre de la Licenciatura en Español y Lenguas Extranjeras de la Universidad Pedagógica Nacional, y el segundo, compuesto por un grupo de 25 estudiantes franceses en primer año de Licenciatura en Enseñanza de Lenguas de la Universidad de Toulouse II-Jean Jaurès.

Como se puede apreciar, la variable principal está definida por la pertenencia de cada participante a una comunidad lingüística, cultural e institucional. Partimos del hecho de que cada grupo de informantes pertenece a un colectivo particular, que se caracteriza por compartir unas visiones de mundo, así como un conjunto de creencias y conocimientos que garantizan que cada uno de sus miembros pueda interpretar el sentido que se da a los enunciados. Igualmente, se puede observar que la característica común que 
define a los informantes es que todos comienzan sus estudios universitarios en docencia de las lenguas extranjeras. De acuerdo con Barbier (2006) esta etapa inicial es primordial en la formación del futuro profesional, ya que durante este proceso el sujeto comienza a construir su propia identidad a partir de los aprendizajes y de los contextos institucionales que lo forman, pues la educación tiene como objetivo el cambio o la evolución del sujeto. En consecuencia, cuando un individuo accede a una comunidad de formación, va a adquirir visiones y representaciones comunes sobre una profesión, puesto que los formadores basan sus conocimientos en modelos de referencia que dictaminan lo que la sociedad espera de un cierto grupo de profesionales.

\section{Resultados: análisis y discusión}

Como vimos en la presentación teórico-metodológica de nuestro estudio, la SPA propone un modelo que estudia el significado léxico y el sentido discursivo. Se busca entonces analizar la construcción de la parte estable del significado léxico a partir de diccionarios, además de estudiar las representaciones que los miembros de una comunidad construyen mediante el discurso cuando definen la palabra estudiante. Con el fin de realizar el análisis de la entidad léxica en cuestión y presentar los resultados obtenidos en cada una de las etapas, procederemos como se indica a continuación.

En primer lugar, expondremos el estudio del corpus lexicográfico. Comenzaremos por presentar el núcleo del término de estudio en español y luego en francés, así como los valores axiológicos que estos núcleos contienen para cada lengua. Finalmente, haremos una comparación con el fin de corroborar el grado de correspondencia, en cuanto a rasgos característicos y valores, entre las dos lenguas. En segundo lugar, analizaremos el corpus conformado por las definiciones dadas por los estudiantes colombianos y franceses del término estudiante. Aquí se presentará el núcleo de la entidad estudiada y sus valores axiológicos. Para esta sección las definiciones del término de estudio se organizarán a partir de tres categorías que, de acuerdo con nuestra perspectiva teórica, constituyen la estructuración de toda actividad profesional. Estas son las cualidades que se le atribuyen al estudiante, las acciones que este Ileva acabo para realizar su actividad profesional y, finalmente, su relación con su entorno y con otros miembros de la comunidad educativa. Los resultados obtenidos nos permitirán contrastar las representaciones de los estudiantes colombianos y de los franceses. Por último, analizaremos las representaciones del estudiante que puedan contribuir a la creación de un diálogo intercultural entre las representaciones identitarias de los estudiantes colombianos y franceses. 


\title{
El término estudiante en los diccionarios de español
}

\author{
El núcleo y sus valores
}

A partir de las definiciones encontradas en los diccionarios de lengua española se estableció el siguiente núcleo (N) para el término estudiante:

$A=$ Quien enseña (entonces un nominal $<+$ humano $>$ )

$\mathrm{B}=$ Quien aprende (entonces un nominal $<+$ humano $>$ )

B se interesa en la comprensión y en el conocimiento del mundo, PLT B cursa estudios, PLT B ejercita el entendimiento, el pensamiento, la inteligencia, PLT B esfuerza sus facultades intelectuales, PLT B alcanza un objetivo gracias a las acciones de $\mathrm{A}^{6}$.

Podemos observar que en español el núcleo de la entidad léxica estudiante está conformado por cinco bloques de significado vinculados entre sí mediante el conector PLT (por lo tanto). Al sujeto que aprende se le asocia la voluntad de realizar esfuerzos intelectuales para conocer el mundo, mientras que a quien enseña se le asocia la idea de mediador, gracias a, que ejerce una acción para asegurar el aprendizaje. El núcleo enmarca la identidad del estudiante y del maestro en una institución donde se van a cursar estudios, lo que pone en evidencia el carácter institucional de la identidad del estudiante.

En cuanto a los valores axiológicos podemos observar que el primer bloque, introducido por el sintagma interesarse en, es portador de valores pragmáticos e intelectuales positivos ${ }^{7}$, autorizados por la presencia de los términos comprensión y conocimiento porque el deseo del individuo de conocer el mundo provoca el interés intelectual y el placer de ejercer el pensamiento para estudiarlo. Observamos también la presencia de valores finalizantes-volitivos ya que el interés nace de la voluntad y del deseo de aprender del estudiante. En cuanto a las entidades comprensión y conocimiento, estas son portadoras de valores intelectuales y pragmáticos positivos debido a la importancia de la comprensión para transformar el pensamiento del sujeto y su entorno. Igualmente identificamos la presen-

6 De acuerdo con nuestra perspectiva teórica y metodológica, el núcleo de una entidad léxica se construye a partir de bloques de significado vinculados mediante los conectores virtuales PLT (por lo tanto) y SE (sin embargo), que representan relaciones normativas y transgresivas, respectivamente (Galatanu, 2007).

7 Según la SPA, el individuo inscribe en las palabras valores modales que pueden ser monovalentes o bivalentes. Las primeras, inscriben en su núcleo o en sus estereotipos uno de los polos axiológicos (negativo o positivo). Las segundas, son portadoras, en sus estratos, de los dos polos, uno de los cuales se activa mediante la movilización discursiva que el sujeto hace de las palabras (Galatanu, 2000b). En el análisis demostraremos qué polo o polos activan los sintagmas que se analizan. 
cia de valores finalizantes y epistémicos, pues el objetivo de estudiar es adquirir nuevos conocimientos, ya que el estudiante se fija unos objetivos de aprendizaje.

En el bloque cursar estudios observamos la presencia de valores aléticos-necesarios y deónticos-obligatorios. En esta parte del núcleo se identifica que la escolarización es la condición para poder acceder a la comprensión del mundo. No obstante, el hecho de decidir formar parte de una institución educativa puede partir de la necesidad de adquirir nuevos conceptos, pero también de la obligación de ilustrarse en una sociedad cuyo capital se basa en el conocimiento. Identificamos también valores finalizantes-volitivos pues normalmente la decisión de educarse o no también depende de la voluntad del individuo o, en algunos casos, de un tercero: los padres de familia, e incluso el Estado.

En el bloque ejercita el entendimiento, el pensamiento, la inteligencia se constata la presencia de valores aléticos-necesarios y deónticos-obligatorios pues el proceso de aprendizaje pasa por la adquisición obligatoria o voluntaria de ciertos hábitos de estudio que aseguran que este ocurra. Percibimos también la presencia de valores finalizantes-volitivos ya que la apropiación de dichos hábitos depende de la voluntad de quien estudia. Para alcanzar los logros de aprendizaje fijados es necesario esforzar las facultades intelectuales, elemento del penúltimo bloque de significado. Aquí identificamos valores hedónico-afectivos ambivalentes, en la medida en que el esfuerzo produce el cansancio físico y la fatiga intelectual del estudiante, lo que activa el polo axiológico negativo, pero del mismo modo estos esfuerzos pueden ser fuente de placer emocional puesto que esforzarse garantiza la adquisición de nuevos conocimientos, lo que activa el polo positivo. Identificamos también valores deónticos-obligatorios porque el estudiante es forzado por sí mismo o por un tercero (normalmente el profesor) a realizar varias acciones intelectuales que lo conducen a aprender.

El último bloque, alcanzar un objetivo, está cargado de valores pragmáticos y hedónico-afectivos positivos, pues el resultado de los esfuerzos se transforma en aprendizajes y en el progreso personal o profesional del alumno. Percibimos también la presencia de valores finalizantes puesto que todo aprendizaje generalmente implica el alcance de un objetivo.

A partir del análisis de los bloques que conforman el núcleo de la entidad estudiante y sus valores podemos establecer lo siguiente: 
Tabla 1

Valores del núcleo de estudiante en español.

\begin{tabular}{lc}
\multicolumn{1}{c}{ Valor } & Ocurrencias \\
\hline Pragmatico (+), finalizante-volitivo & 6 \\
Intelectual (+) & 4 \\
Alético (necesario), deóntico (obligatorio) & 2 \\
Epistémico & 2 \\
Hedónico-afectivo $(+)(-)$ & 2 \\
\hline
\end{tabular}

Fuente: elaboración propia.

Como se puede observar, para la entidad estudiante predominan los valores axiológicos y finalizantes. En cuanto al primer grupo, priman los valores intelectuales y pragmáticos positivos pues el interés del estudiante por conocer y adquirir nuevas habilidades lo lleva a progresar espiritual y materialmente. De la misma manera, el aprendizaje se manifestaría a través de un resultado, que se traduce en la adquisición de conocimientos o habilidades. En cuanto al segundo grupo, sobresalen los valores finalizantes-volitivos, ya que la decisión de aprender y de realizar esfuerzos depende únicamente de la voluntad de quien se compromete a aprender, aun si hay terceros que deciden el inicio y el tipo de escolarización de los individuos. Del mismo modo, observamos que la entidad estudiante activa valores aléticos-necesarios y deónticos-obligatorios, en la medida en que el sujeto puede percibir la educación como una oportunidad para progresar o como una imposición de la sociedad. Vemos igualmente que el ejercicio del pensamiento y los esfuerzos intelectuales activan valores hedónico-afectivos ambivalentes, pues estas actividades intelectuales provocan el cansancio del estudiante al mismo tiempo que son una fuente de satisfacción cuando se alcanza una meta. Finalmente, la noción estudiante está cargada de valores epistémicos debido a la relación del aprendizaje con el saber científico.

\section{El término étudiant en los diccionarios de francés}

\section{El núcleo y sus valores}

A partir de las definiciones encontradas en los diccionarios de lengua francesa referenciados, se constituyó el siguiente núcleo $(\mathrm{N})$ para el término étudiant. Damos cuenta directamente de nuestra traducción del análisis al español.

$\mathbf{A}=$ Quien enseña (entonces un nominal $<+$ humano $>$ )

$\mathbf{B}=$ Quien aprende (entonces un nominal <+humano $>$ ) 
B aspira a adquirir conocimientos o habilidades PLT B hace estudios PLT B ejerce el pensamiento, el entendimiento, la inteligencia o la experiencia PLT B se vuelve capaz de conocer o de hacer gracias a la intervención de A.

En francés el núcleo lo conforman cuatro grandes bloques de significado vinculados entre sí por relaciones normativas. De manera general, se puede percibir la correspondencia con los bloques que constituyen el núcleo de la entidad estudiante en español. Por un lado, porque estos bloques otorgan la casi totalidad de la responsabilidad del aprendizaje al estudiante y dan al profesor un rol de intermediario (gracias a la intervención). Por otro, porque enmarca la adquisición de los conocimientos en un ámbito institucional (hacer estudios).

De acuerdo con la definición, el estudiante aspira a adquirir conocimientos o habilidades, es decir que tiene un infinito deseo de comprender el mundo y por lo tanto hará lo que esté a su alcance para poder aprender. Encontramos entonces que el término aspirar activa valores finalizantes-volitivos puesto que la entidad hace referencia a la voluntad y al deseo del estudiante de alcanzar un objetivo, el aprendizaje. Por un lado, la palabra adquirir está impregnada de valores pragmáticos positivos y finalizantes-volitivos, pues la adquisición de un conocimiento o de una habilidad es útil para el desarrollo y el progreso profesional de un individuo; dicha tarea depende de la voluntad de quien aprende. Por otro lado, las ocurrencias que acompañan esta acción, conocimientos y habilidades, activan valores pragmáticos, epistémicos e intelectuales positivos, pues el conocimiento es motivado por la curiosidad del ser humano acerca del mundo, y su adquisición contribuye a transformarlo. Este aprendizaje se realiza cuando $B$ hace estudios; en este sintagma observamos la presencia de valores aléticos-necesarios y deónticos-obligatorios, pues la voluntad de escolarizarse puede ser el resultado de una necesidad de aprender o de una obligación impuesta.

Para poder ejecutar este proceso de adquisición de conocimientos o habilidades hace falta realizar esfuerzos que conduzcan al aprendizaje. De acuerdo con nuestro corpus se haría entonces necesario ejercer el pensamiento (exercer l'esprit, en francés). Según el diccionario francés Le Grand Robert 2011, el sintagma exercer l'esprit remite a la idea de "someterse a una preparación metódica con el fin de adquirir conocimientos o habilidades". Por ende, se constata la presencia de valores aléticos-necesarios y deónticos-obligatorios, puesto que el deseo de aprender obliga a los estudiantes a adoptar un método riguroso de preparación que permita alcanzar los objetivos intelectuales y profesionales que se proponen. Igualmente, la entidad exercer está acompañada de valores hedónicos-afectivos ambivalentes, pues dicha acción exige del estudiante un esfuerzo intelectual y físico, al mismo tiempo que otorga

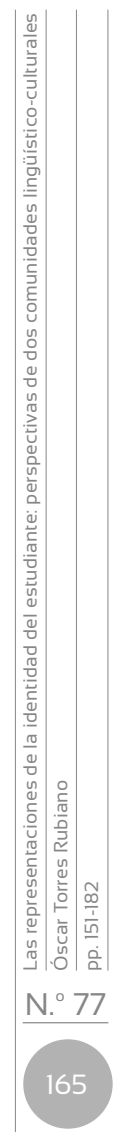


la satisfacción de la consagración. La entidad léxica que acompaña este verbo en francés es esprit, que se puede traducir en español como pensamiento, comprensión. En fin, hace referencia a la sustancia pensante y al sujeto que conoce el mundo. En consecuencia, esta ocurrencia porta valores ontológicos y finalizantes, pues es a través del esprit como el ser humano conoce el mundo, lo juzga y lo transforma. Por otro lado, el termino inteligencia hace referencia a la función mental que organiza el mundo objetivo en pensamientos; en consecuencia, activa valores pragmáticos e intelectuales positivos pues la inteligencia es útil para realizar las actividades de aprendizaje que el estudiante se propone. Finalmente, el termino experiencia está cargado de valores pragmáticos e intelectuales positivos, puesto que los conocimientos adquiridos a lo largo de la vida permiten discernir y confrontar la construcción propia del mundo con la de los demás, lo que hace que el individuo actúe de manera más eficaz durante la realización de una tarea.

El cuarto bloque está conformado por la forma devenir capable, que tradujimos en español por hacerse capaz. El verbo devenir ('hacerse', 'convertirse') contiene valores finalizantes-volitivos porque se trata de poner en acción la voluntad de realizar un cambio de estado en el individuo. Este verbo activa valores pragmáticos positivos porque este cambio contribuye a la transformación del sujeto. En cuanto al término capaz, se activan valores pragmáticos positivos y finalizantes-volitivos puesto que la capacidad de hacer algo permite al individuo ejercer una función específica en su mundo profesional. Igualmente, este término encierra valores hedónico-afectivos positivos debido al sentimiento de satisfacción que produce la adquisición de nuevas competencias. La tabla 2 condensa los valores que activan los elementos del núcleo del término estudiante en francés.

\section{Tabla 2}

Valores del núcleo de estudiante en francés.

\begin{tabular}{lc}
\multicolumn{1}{c}{ Valor } & Ocurrencias \\
\hline Pragmático (+), finalizante-volitivo & 7 \\
Intelectual (+) & 2 \\
Alético (necesario), déontico (obligatorio) & 1 \\
Epistémico & 2 \\
Hedónico-afectivo $(+)(-)$ & 2 \\
\hline
\end{tabular}

Fuente: elaboración propia.

Como en el caso del español, observamos que en francés predominan los valores axiológicos y finalizantes-volitivos en lo que respecta a los valores del núcleo. Constatamos una fuerte presencia de valores pragmáticos, pues 
la actividad profesional del estudiante, es decir el aprendizaje, contribuye a la transformación y evolución del individuo. También corroboramos la presencia de valores intelectuales positivos ya que el aprendizaje implica actividades de orden intelectual y cognitivo; este proceso resulta del interés y de la curiosidad del estudiante por comprender el mundo. Asimismo se aprecian valores hedónicos-afectivos en la medida en que el aprendizaje se adquiere a través del esfuerzo, que produce cansancio y satisfacción en el estudiante. Se corrobora la fuerte presencia de valores finalizantes-volitivos porque el aprendizaje depende esencialmente de la voluntad de aprender del estudiante. Finalmente, se observa la aparición de valores epistémicos que están relacionados con el mundo del conocimiento y los saberes científicos.

\section{Comparación entre los núcleos y sus valores en español y francés (corpus lexicográfico)}

En lo que respecta a la configuración del núcleo para las dos lenguas, debemos subrayar que la entidad estudiante está constituida por un atributo de sujeto (nominal <+humano $>$ ) que remite a dos aspectos complementarios del funcionamiento de los individuos en las estructuras sociales. Por un lado, el estudiante se define como el actor de su aprendizaje (ejerce el pensamiento, realiza esfuerzos, hace estudios), pero al mismo tiempo está sujeto, determinado y constituido por un sistema de relaciones y de obligaciones frente a las instituciones escolares que lo acogen.

A primera vista se puede afirmar que para las dos lenguas los rasgos estables del significado léxico son comunes, lo que nos conduce a inclinarnos hacia la hipótesis universalista del significado que afirma que toda entidad léxica posee rasgos semánticos universales, y que esas características comunes hacen posible la comprensión entre distintas comunidades lingüísticas y culturales (Galatanu, 2009).

Los núcleos de la entidad estudiante en español y francés parten de la base de una construcción dialógica en la cual la identidad del estudiante, representada en el núcleo por B, se construye alrededor de la del profesor, representada por A. En los diccionarios, el estudiante parte de su voluntad de querer aprender, en tanto que el profesor guía esos procesos de aprendizaje. De acuerdo con nuestro corpus lexicográfico, sin la intervención del profesor no habría aprendizaje.

Por otro lado, la curiosidad y el interés por el conocimiento serían la fuente que motiva la voluntad y el deseo de aprender. Esto nos lleva a pensar que el estudiante se define por su actividad profesional, o sea el aprendizaje, que implica el esfuerzo intelectual y la adopción de métodos que lo conduzcan a adquirir nuevos conocimientos o habilidades. Del mismo modo se observa que con frecuencia en los diccionarios se define al estudiante por la acción de seguir un programa de estudios, es decir, 
por el hecho de estar escolarizado, lo que constituye parte esencial de su identidad profesional. Por ende, la profesión "estudiante" se define ampliamente por la pertenencia del individuo que aprende a un sistema escolar.

Nuestra argumentación nos lleva a concluir que los núcleos de la entidad léxica estudiante en español y francés corresponden en su totalidad. En primer lugar, porque en los dos casos el interés y el deseo de conocer provocan la movilización de esfuerzos intelectuales del estudiante; en segundo lugar, porque en estas dos lenguas se ponen de relieve el rol de profesor y la voluntad del alumno como garantes del aprendizaje del estudiante.

Esta correspondencia entre los núcleos se constata también si observamos las ocurrencias de los valores movilizados en las dos lenguas. Así se podrá corroborar que el término estudiante activa, en español y francés, valores pragmáticos, epistémicos e intelectuales positivos, en la medida en que la adquisición de conocimientos y habilidades es útil para el desarrollo y la evolución personal y profesional del individuo. Se observó igualmente una fuerte presencia de valores finalizantes-volitivos, puesto que el estudiante pone a prueba su voluntad con el fin de alcanzar unos objetivos de aprendizaje. Sin embargo, la decisión de aprender se puede ver como una necesidad o una obligación, lo que nos lleva a identificar la presencia de valores aléticos y deónticos porque el aprendizaje se asocia a una actividad necesaria para participar en las estructuras sociales o a una actividad impuesta a todos los seres humanos, lo que conlleva un sentido de obligación. Finalmente, las dos lenguas activan valores hedónico-afectivos ambivalentes porque el aprendizaje, en cuanto proceso cognitivo, pide al estudiante realizar constantes esfuerzos intelectuales y físicos, fuente de agotamiento y al mismo tiempo de satisfacción por las metas logradas.

\section{El término estudiante en el discurso de los informantes colombianos}

\section{El núcleo}

Recordemos que el núcleo que presentaremos se construyó a partir de las respuestas de los estudiantes colombianos a dos partes del cuestionario. Puesto que estas preguntas persiguen el mismo objetivo, conocer la parte estable de la significación, condensamos las respuestas en la tabla 3. Estas se organizaron en tres grandes categorías que corresponden a los elementos que estructuran una profesión: las cualidades y las actividades profesionales que se le atribuyen al estudiante, así como su relación con el entorno. Estos rasgos constituyen el núcleo de la entidad estudiante para los informantes colombianos. Las respuestas se presentan de la 
siguiente manera: a la derecha se encuentran las palabras con las que los participantes colombianos definieron el término estudiante y a la izquierda el número de ocurrencias detectadas en el corpus.

\section{Tabla 3}

Núcleo del término "estudiante" en las definiciones de los estudiantes colombianos.

\begin{tabular}{|c|c|}
\hline \multicolumn{2}{|c|}{ Cualidades } \\
\hline Estudiante PLT & N. ${ }^{\circ}$ \\
\hline Dedicado & 8 \\
\hline Responsable & 7 \\
\hline Comprometido con sus estudios & 7 \\
\hline Obligado a aprender & 5 \\
\hline Autónomo en el aprendizaje & 4 \\
\hline Motivado a aprender & 4 \\
\hline Riguroso & 4 \\
\hline Crítico de su entorno & 4 \\
\hline Estudioso & 3 \\
\hline
\end{tabular}

\section{Actividades profesionales}

$\begin{array}{ll}\text { Recibir y acumular conocimiento } & 21\end{array}$

Construir el conocimiento $\quad 20$

$\begin{array}{ll}\text { Construir una mejor sociedad } & 14\end{array}$

Esforzarse para superarse 11

Ir a una institución educativa

Aprender 9

Aplicar el conocimiento 8

$\begin{array}{ll}\text { Alcanzar un logro } & 7\end{array}$

Ser competente para insertarse en el mundo laboral 6

Ir más allá del conocimiento brindado 6

Escalar socialmente $\quad 5$

\section{Relación con el entorno}

Guiado por un maestro

Representa el futuro de la nación

El profesor le brinda conocimiento 
De acuerdo con las respuestas de los participantes colombianos se puede concluir que la identidad del estudiante se define primordialmente por la voluntad de adquirir nuevos conocimientos y habilidades, así como por su inscripción en un marco institucional, pues el estudiante se define como quien va a una institución educativa. No obstante, observamos que no hay unanimidad en cuanto a la manera en que el alumno adquiere estos conocimientos. Para la mayoría de los encuestados el aprendizaje es un proceso de recepción, para otra parte es una construcción personal y para otra es una construcción conjunta entre el estudiante y el maestro. Esto nos lleva a pensar que en el discurso de los estudiantes colombianos coexisten por lo menos dos representaciones identitarias del estudiante que están en tensión.

Esto se ve reflejado en las ocurrencias asociadas a las actividades profesionales del estudiante que sintetizamos en la tabla 3. Por una parte, se observa que la acción con mayor número de ocurrencias es recibir y acumular conocimientos (21 ocurrencias), este sintagma se puede asociar a la imagen del alumno como un actor pasivo que es obligado (5) a aprender. En primer lugar, el verbo recibir implica unidireccionalidad, pues hace referencia a un sujeto-receptor que acepta de manera pasiva lo que se le da o lo que se transmite, en este caso el conocimiento. En segundo lugar, la entidad acumular remite a la idea de que el aprendizaje se realiza cuando el estudiante ha podido reunir una gran cantidad de conocimientos que le servirán para demostrar la eficacia de su acción, es decir aprender. A esta imagen del estudiante corresponde una para el profesor, quien es considerado la persona que brinda el conocimiento (4), lo que refuerza la idea de un sujeto que da y otro que recibe. Podríamos suponer que dicha representación está profundamente arraigada en los estudiantes debido a sus experiencias personales de aprendizaje y que son reproducidas por las instituciones escolares.

En oposición a esta representación, los informantes colombianos también evocaron una imagen del estudiante como el sujeto que construye el conocimiento (20 ocurrencias). De acuerdo con el DRAE el verbo construir hace referencia a "la realización de algo a partir de ciertos elementos que respetan unas reglas y una coherencia"; por lo tanto, esta entidad nos permite inferir que el aprendizaje se concibe como un proceso cognitivo en el cual el estudiante pone en acción estrategias y métodos organizados que le permiten construir el conocimiento. Desde esta perspectiva identificamos dos imágenes del estudiante. La primera como alguien autónomo en el aprendizaje (4) que construye sus conocimientos y sus maneras de conocer a partir de sus experiencias y de su rigor (4), además de ser alguien que va más allá del conocimiento brindado (6). La segunda, es el estudiante que se encarga de construir sus propios conceptos e interpretaciones, mientras que el maestro tendría como tarea ayudarlo a forjar esos métodos que aseguran 
el aprendizaje. A la imagen del estudiante como sujeto constructor del conocimiento corresponde la del profesor como guía (8).

Suponemos que estas dos representaciones identitarias tan distintas cohabitan en el discurso de los futuros profesores de lenguas colombianos en la medida en que coexisten dos elementos que forjan la imagen de lo que significa aprender. Por un lado, estarían las experiencias escolares en donde el estudiante efectivamente debe memorizar y acumular conocimientos para luego repetirlos. Por otro lado, estarían las representaciones vehiculadas por su formación como docentes que definen el proceso de aprendizaje como una co-construcción entre el estudiante y el profesor. De tal manera, la cohabitación de dos imágenes identitarias distintas no constituye una paradoja, de hecho, los estudiantes asumirían uno u otro rol en función de los contextos de aprendizaje. En fin, los observables semánticos permiten detectar una tensión entre dos representaciones identitarias del estudiante específicamente a través de verbos que implican o una acción pasiva (recibir, acumular) o una acción activa (construir).

Otro elemento que llama nuestra atención y que definiría para los informantes colombianos al estudiante es su compromiso ciudadano con la sociedad que contribuye a su formación. De acuerdo con los participantes, el estudiante es el futuro de una nación (7 ocurrencias), y la adquisición de conocimientos y competencias sería la herramienta que les permitiría construir una mejor sociedad (14). El aprendizaje se percibe como un elemento transformador del entorno y creador del progreso para la colectividad. Con el fin de poder participar en ese progreso, el aprendizaje debe permitir alcanzar un logro (7), lo que se traduce en la adquisición de conocimientos que lo hagan aprender (9) o ser competente para insertarse en el mundo laboral (8). La participación del estudiante en la estructura productiva y económica de su sociedad aseguraría que se sintiera pleno al mismo tiempo que participaría en la construcción de su sociedad.

Para que el proceso de aprendizaje pueda ponerse en marcha el estudiante debe caracterizarse por un saber ser. El estudiante debe ser responsable (7) y comprometido en los estudios (7); igualmente, debe poseer un saber metódico que le permitirá organizar e interpretar los conocimientos, es decir, debe ser riguroso (6).

\section{El término étudiant en el discurso de los estudiantes franceses}

\section{El núcleo}

Los rasgos que constituyen el núcleo de la entidad estudiante para los informantes franceses se sintetizan en la tabla 4. 


\section{Tabla 4}

Núcleo del término estudiante en las definiciones de los estudiantes franceses.

\begin{tabular}{|c|c|}
\hline \multicolumn{2}{|c|}{ Cualidades } \\
\hline Estudiante PLT & N. ${ }^{\circ}$ \\
\hline Interesado & 4 \\
\hline Motivado & 3 \\
\hline Dinámico & 3 \\
\hline De mente abierta & 3 \\
\hline Organizado & 3 \\
\hline Autónomo & 2 \\
\hline Aplicado & 2 \\
\hline
\end{tabular}

\section{Actividades profesionales}

Adquirir conocimientos

Aprender un saber-hacer

Asistir a clases

8

Validar saberes (durante los exámenes)

Buscar el saber en la universidad

Hacerse competente (para ejercer una profesión)

Servir a la nación

Aprender para adquirir saberes demasiado teóricos 3

\section{Relación con el entorno}

Aprender gracias a los libros

Aprender por intermedio de un profesor

Fuente: elaboración propia.

Al igual que los estudiantes colombianos, los franceses construyen una doble representación del estudiante que se basa particularmente en el sentido que se le otorga al aprendizaje. Estas imágenes tienen estrecha relación con las prácticas institucionales francesas, en donde la adquisición de los conocimientos o habilidades se evalúa exclusivamente en los exámenes de final de año. A continuación, explicamos nuestro argumento.

Al observar la columna correspondiente a las actividades profesionales corroboramos que la ocurrencia más activada es adquirir conocimientos (19) y en seguida aprender un saber hacer (11 ocurrencias). Estas acciones marcan una oposición entre un saber teórico e intelectual que se aprende gracias a los libros (4) y un saber-hacer que se adquiere por intermedio del profesor (3) y en general gracias a la escolarización, razón 
por la cual una de las acciones principales del estudiante se enmarca en la institución educativa, pues el alumno aprende porque asiste a clase (8) y porque allí puede buscar el saber (4).

Esta oposición entre un conocimiento teórico y otro práctico se hace sentir en las formas institucionales que permiten legitimar la validación de la adquisición de conocimientos y habilidades. Por un lado los conocimientos prácticos servirían para integrarse en la estructura productiva de una sociedad ya que permiten a quien aprende hacerse competente para ejercer una profesión (4); es decir, la legitimación del conocimiento se hace en este caso demostrando y aplicando la habilidad adquirida por el estudiante para desempeñarse en una actividad productiva. Por otro lado, los conocimientos teóricos se traducirían en saberes intangibles que servirían primordialmente para validar los exámenes. Este tipo de aprendizaje es juzgado como inútil debido a que se adquiere exclusivamente para fines evaluativos y porque no conduce a una aplicación tangible en el mundo laboral.

Esta aseveración es soportada por las definiciones de por lo menos la mitad de los participantes galos, quienes juzgan como negativa la imagen del estudiante que debe aprender exclusivamente para la validación de los exámenes. Esta certificación de conocimientos no contribuiría a la adquisición de competencias laborales. Con el fin de reforzar nuestra hipótesis traemos a colación una definición que nos parece representativa de este punto de vista. Esta es la respuesta de uno de los participantes cuando se le pide definir el término estudiante para su sociedad:

Estudiante: Un individuo que en cualquier edad se lanza a aprender para adquirir una competencia, en Francia, sobre todo en la óptica de una evaluación, en lo que concierne al Ministerio de Educación, se trata de una opinión ampliamente compartida pero no es la mía ${ }^{8}$. (Participante 17).

En esta definición se corroboran estas dos representaciones del aprendizaje. Por un lado está el deseo de volverse competente para realizar una labor, y por el otro, hay una obligación institucional, representada aquí por el Ministerio, que obliga al estudiante a validar sus competencias a través del examen. Esta perspectiva de análisis se confirma por la presencia del sintagma Aprender para adquirir saberes demasiado teóricos (3), lo que deja en claro que los estudiantes poseen dos visiones de lo que es

8 «Un individu qui a tout âge se lance dans un apprentissage pour acquérir une compétence en France, plutôt dans l'optique d'une évaluation en ce qui concerne l'éducation nationale c'est un avis largement partagé, pas le mien.» (Participante 17). 
aprender: adquirir conocimientos teóricos para ser evaluado y poder tener una certificación (nota, diploma) o hacerse competente para ingresar al mundo laboral y servir a la nación (3).

En cuanto a las cualidades, los informantes franceses consideran que los estudiantes deben mostrarse interesados (4), motivados (3) y dinámicos (3) pues la adquisición del conocimiento pasa por la curiosidad que suscita el deseo de comprender el mundo, así como por la consagración y el entusiasmo para lograr los objetivos del aprendizaje. La adquisición de conocimientos y competencias puede ocurrir si los estudiantes son de mente abierta (2); dicha característica asegura que los estudiantes se interesen y comprendan nuevos paradigmas cognitivos, culturales e intelectuales.

En conclusión, el estudiante, de acuerdo con las representaciones provenientes del núcleo construido a partir de las respuestas de los informantes franceses, es un ser que se inscribe en una institución escolar que le otorga los elementos físicos (libros) y humanos (profesor) para adquirir el conocimiento y las habilidades que le permitan ser competentes e ingresar al mundo laboral. Para que el aprendizaje se produzca el estudiante debe comprometerse y responsabilizarse de la adquisición o búsqueda de los saberes. A esta definición se contrapone otra representación construida por las obligaciones institucionales que llevan al estudiante a definirse como un sujeto que se prepara intelectualmente para validar exámenes, ya que esta es una de las formas principales para certificar institucionalmente los aprendizajes.

\section{Hacia un diálogo intercultural: comparación entre el núcleo lexicográfico y las definiciones de los participantes colombianos y franceses}

En esta sección nos proponemos realizar un análisis comparativo entre tres elementos: (1) el núcleo obtenido gracias a la comparación de las definiciones del término estudiante obtenidas en el corpus lexicográfico en español y en francés, (2), las definiciones propuestas por los estudiantes colombianos y (3) las definiciones brindadas por los estudiantes franceses.

La primera labor se concentrará en identificar los rasgos estables y esenciales del término estudiante que son comunes tanto para el corpus lingüístico como para las definiciones dadas por los participantes. Estas propiedades semánticas serían consideradas como universales puesto que toda comunidad lingüístico-cultural compartiría los mismos rasgos, fenómeno que asegura la intercomprensión. Para efectos de nuestra investigación, estas propiedades universales son el punto de partida para nuestra proposición de diálogo intercultural entre nuestras dos comunidades. La segunda tarea consistirá en contrastar los dos núcleos construidos a partir de las definiciones 
de los informantes colombianos y franceses. El objetivo es identificar los elementos de comprensión entre estas dos comunidades respecto a sus representaciones del estudiante.

La tabla número 5 presenta la relación de los bloques de significado del núcleo obtenidos en primer lugar en los diccionarios, enseguida en los discursos de los estudiantes colombianos y finalmente en los discursos de los estudiantes franceses. Nótese que para los estudiantes proponemos dos núcleos (R1, R2) pues los estudiantes propusieron dos imágenes identitarias diferentes. Los bloques de significado están organizados en las tres categorías que definen una identidad profesional, es decir las acciones, las relaciones con el entorno y las cualidades.

$$
\begin{aligned}
& \mathbf{A}=\text { Quien enseña (entonces un nominal }<+ \text { humano }>\text { ) } \\
& \mathbf{B}=\text { Quien aprende (entonces un nominal }<+ \text { humano }>\text { ) }
\end{aligned}
$$

\section{Tabla 5}

\begin{tabular}{|c|c|c|c|c|c|}
\hline \multirow[t]{2}{*}{$\begin{array}{l}\text { Categorías } \\
\text { que definen } \\
\text { la profesión } \\
\text { estudiante }\end{array}$} & \multirow{2}{*}{$\begin{array}{c}\text { Núcleo } \\
\text { lingüístico } \\
\text { Estudiante } \\
\text { PLT } \\
\text { Diccionarios en } \\
\text { español y en } \\
\text { francés }\end{array}$} & \multicolumn{2}{|c|}{$\begin{array}{c}\text { Definición } \\
\text { (colombianos) } \\
\text { Estudiante PLT }\end{array}$} & \multicolumn{2}{|c|}{$\begin{array}{c}\text { Definición } \\
\text { (franceses) } \\
\text { Estudiante PLT }\end{array}$} \\
\hline & & $\begin{array}{c}\text { R1 } \\
\text { Insatisfecho }\end{array}$ & $\begin{array}{c}\text { R2 } \\
\text { Realizado }\end{array}$ & $\begin{array}{c}\text { R1 } \\
\text { Insatisfecho }\end{array}$ & $\begin{array}{c}\text { R2 } \\
\text { Realizado }\end{array}$ \\
\hline Acciones & $\begin{array}{c}\text { B aspira a / } \\
\text { se interesa } \\
\text { por adquirir } \\
\text { conocimientos o } \\
\text { habilidades } \\
\text { PLT } \\
\text { B hace estudios } \\
\text { PLT } \\
\text { B ejerce el } \\
\text { pensamiento, el } \\
\text { entendimiento, la } \\
\text { inteligencia o la } \\
\text { experiencia } \\
\text { PLT } \\
\text { B esfuerza } \\
\text { sus facultades } \\
\text { intelectuales } \\
\text { PLT } \\
\text { B se vuelve capaz } \\
\text { de conocer o de } \\
\text { hacer }\end{array}$ & $\begin{array}{c}\text { B es obligado a } \\
\text { aprender } \\
\text { PLT } \\
\text { B va a una institu- } \\
\text { ción educativa } \\
\text { PLT } \\
\text { B Recibe y } \\
\text { acumula conoci- } \\
\text { miento de A } \\
\text { PLT } \\
\text { B aprende }\end{array}$ & $\begin{array}{c}\text { B desea adquirir } \\
\text { conocimientos y ser } \\
\text { competente } \\
\text { PLT } \\
\text { B va a una institución } \\
\text { educativa } \\
\text { PLT } \\
\text { B construye el conoci- } \\
\text { miento guiado por A } \\
\text { P } L T \\
\text { B se esfuerza } \\
\text { P } L T \\
\text { B busca el conoci- } \\
\text { miento fuera de A } \\
\text { P } L T \\
\text { B alcanza un logro } \\
P L T \\
\text { B es competente para } \\
\text { el mundo laboral } \\
P L T\end{array}$ & $\begin{array}{c}\text { B desea adquirir } \\
\text { conocimientos y } \\
\text { habilidades } \\
\text { PLT } \\
\text { B busca el } \\
\text { saber en una } \\
\text { institución } \\
\text { PLT } \\
\text { B va a clases } \\
\text { SE } \\
\text { Adquiere } \\
\text { saberes } \\
\text { demasiado } \\
\text { teóricos } \\
\text { PLT } \\
\text { A evalúa los } \\
\text { saberes teóricos } \\
\text { de B } \\
\text { SE } \\
\text { B no es } \\
\text { competente }\end{array}$ & $\begin{array}{c}\text { B desea adquirir } \\
\text { conocimientos y } \\
\text { habilidades } \\
\text { PLT } \\
\text { B busca el saber } \\
\text { en una institución } \\
\text { PLT } \\
\text { B va a clases } \\
\text { PLT } \\
\text { adquiere un saber- } \\
\text { hacer } \\
\text { PLT } \\
\text { se hace } \\
\text { competente para } \\
\text { una profesión } \\
\text { PLT } \\
\text { Sirve a la nación }\end{array}$ \\
\hline $\begin{array}{l}\text { Relación con el } \\
\text { entorno }\end{array}$ & $\begin{array}{c}\text { B aprende gracias } \\
\text { a la intervención } \\
\text { de A }\end{array}$ & $\begin{array}{l}\text { A brinda el cono- } \\
\text { cimiento a B }\end{array}$ & $\begin{array}{c}\text { B es guiado por } A \\
\text { A exige esfuerzo a } B\end{array}$ & $\begin{array}{l}\text { B aprende por } \\
\text { intermedio de A }\end{array}$ & $\begin{array}{l}\text { B aprende por } \\
\text { intermedio de A }\end{array}$ \\
\hline Cualidades & $\begin{array}{l}\text { Interesado } \\
\text { Aplicado }\end{array}$ & $\begin{array}{l}\text { Dependiente } \\
\text { Desinteresado }\end{array}$ & $\begin{array}{c}\text { Dedicado Responsa- } \\
\text { ble Comprometido } \\
\text { Autónomo Crítico } \\
\text { Estudioso }\end{array}$ & & $\begin{array}{l}\text { Interesado } \\
\text { Aplicado } \\
\text { Autónomo } \\
\text { Dinámico } \\
\text { De mente abierta } \\
\text { Organizado }\end{array}$ \\
\hline
\end{tabular}

Comparación entre el núcleo lexicográfico y las definiciones de los participantes. 


\section{Propiedades esenciales de la identidad del estudiante}

Al observar los tres núcleos, se puede constatar que el estudiante se define como un sujeto-pensante cuyo deseo por aprender está motivado por su voluntad e interés personales por conocer su entorno y ser competente para el mundo laboral. Estas motivaciones estarían marcadas por la naturaleza humana caracterizada por la curiosidad que le produce el mundo que lo rodea y por la necesidad de desarrollar ciertas competencias manuales, sociales o intelectuales que garanticen su inserción en la sociedad. Dichas características que definen la representación del estudiante activan valores finalizantes-volitivos porque la voluntad del estudiante provoca el aprendizaje; del mismo modo se identifican valores intelectuales positivos que resultan de la curiosidad por conocer.

No obstante, las definiciones proporcionadas por nuestros informantes se diferencian del núcleo construido a partir de los diccionarios, ya que los encuestados colombianos y franceses hacen hincapié en la idea de que el estudiante se educa primordialmente para adquirir competencias que le permitan desempeñarse en el mundo laboral, rasgo que no se encuentra en la definición lexicográfica. Dicha representación está impregnada de valores pragmáticos y hedónico-afectivos positivos debido a que el aprendizaje se evalúa como útil para el desarrollo del individuo que se siente satisfecho cuando es capaz de hacer algo. Suponemos que esta actualización del núcleo, operada en los discursos de los estudiantes, se justifica en la medida en que los informantes se preparan en una institución de educación superior con miras a ejercer una profesión, en este caso profesores de lenguas extranjeras. Es decir, el estudiante no solo está motivado por un conocimiento desinteresado de su entorno, sino sobre todo porque el adquirir conocimientos y competencias garantizaría, o por lo menos facilitaría, su integración en el mundo profesional. Podríamos suponer que dicha representación está fuertemente motivada por las expectativas de una sociedad en donde prima el capital, pues en el mundo occidental el conocimiento y las habilidades se han transformado en formas de capital simbólico que condicionan la participación y la posición en la sociedad de los miembros de una comunidad.

Los tres núcleos enmarcan al estudiante en la institución educativa, pues el aprendizaje y su legitimación (mediante diplomas, notas etc.) solo se pueden realizar dentro de un sistema educativo que regule las relaciones entre los miembros de esta comunidad y el conocimiento. Los encadenamientos $B$ va a una institución educativa y $B$ va a clases activan primordialmente valores aléticos y deónticos en la medida en que el estudiante considera que el sistema educativo es necesario, ya que esta institución se encarga de poner a su servicio los elementos físicos y humanos para realizar el aprendizaje; pero al mismo tiempo, la institución 
educativa se puede percibir como un centro coercitivo donde el estudiante es evaluado por un tercero: $A$ evalúa los saberes teóricos de $B$, como se manifiesta en las respuestas de los informantes franceses.

La voluntad de conocer y adquirir habilidades conduce al estudiante a realizar esfuerzos físicos y cognitivos que aseguren el éxito de su aprendizaje. El esfuerzo de las facultades intelectuales constituye un rasgo común a todas las representaciones. Tanto las definiciones lexicográficas como las de nuestros participantes definen al estudiante como un sujeto que emplea su fuerza física y mental para alcanzar sus metas de aprendizaje. Esta representación activa valores hedónico-afectivos ambivalentes en la medida en que el esfuerzo provoca agotamiento y satisfacción por el trabajo cumplido. Sin embargo, debemos señalar que los participantes solo asocian el esfuerzo físico e intelectual con las representaciones del grupo R2, es decir aquellas en donde el aprendizaje es significativo y conduce a la inserción laboral o brinda la oportunidad a los estudiantes de hacerse ciudadanos: servir a la nación o representar el futuro de la nación. Por ejemplo, los encuestados colombianos asocian el aprendizaje significativo con la acción de esfuerzo: $B$ se esfuerza, mientras que los participantes franceses lo asocian a características tales como interesado, aplicado o autónomo. Por el contrario, en las representaciones del grupo R1, asociadas al aprendizaje por obligación, no detectamos indicadores semánticos del esfuerzo. Esto nos lleva a concluir que para nuestros dos grupos de encuestados el aprendizaje significativo, que se traduce normalmente en la empleabilidad o en su participación como ciudadanos, es una condición para que el estudiante haga los esfuerzos y sacrificios necesarios para el aprendizaje. El último bloque de significado compartido por el corpus lexicográfico y por las definiciones dadas por los participantes atañe a la relación estudiante-profesor y se expresa en el sintagma $B$ aprende gracias a la intervención de $A$. Este rasgo nos muestra que, así como la identidad del estudiante está enmarcada por un contexto institucional, esta se construye a partir de una oposición identitaria representada por la imagen del docente. Esta oposición se construye en una relación de complementariedad entre un sujeto que no conoce, pero desea adquirir saberes, y Otro sujeto que posee el conocimiento y las estrategias que aseguran el aprendizaje. Por ende, la identidad del estudiante se define por la presencia de un profesor. Aun en los núcleos de los estudiantes colombianos y franceses que definen al estudiante como un ser autónomo y capaz de ir más allá de lo que enseña el maestro, los dos grupos reconocen la importancia de la labor pedagógica en la co-construcción del conocimiento.

En conclusión, sin importar la comunidad lingüístico-cultural en la que nos inscribamos, el estudiante se define como un sujeto-pensante cuyo interés por comprender el mundo y adquirir nuevas habilidades es producido por un deseo de progreso intelectual y material. El estudiante se

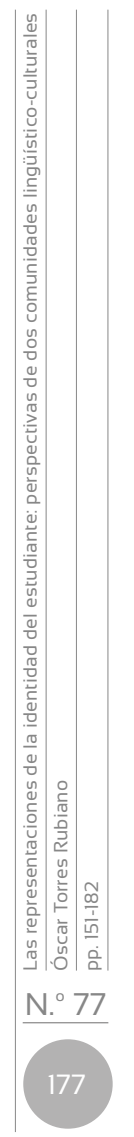


inscribe y se define necesariamente por su inscripción en una institución educativa que asegura su ingreso en las estructuras sociales, intelectuales y productivas de la sociedad a la que pertenece. Es decir, el estudiante se define como un sujeto social en interacción permanente y cuya identidad se define en relación con la de su profesor quien guía los aprendizajes. No obstante, en las definiciones dadas por los encuestados identificamos un rasgo que no aparece en el corpus lexicográfico: el estudiante solo hace efectiva su acción de aprender cuando se encuentra en contextos altamente significativos que garantizan su inserción profesional y su participación como ciudadano. En consecuencia, el docente puede ser percibido como un obstáculo para el aprendizaje ( $A$ evalúa los saberes de $B$ SE $B$ no es competente), o como un profesional con conocimientos insuficientes para construir el conocimiento (B busca el conocimiento fuera de $A$ ).

Estos elementos podrán constituir la base de un diálogo intercultural en cuanto a la comprensión de la identidad profesional del estudiante en nuestros contextos de estudio.

\section{Comparación entre las definiciones de los estudiantes colombianos y franceses}

En los discursos de los participantes colombianos y franceses se puede percibir una tensión entre dos representaciones antinómicas del estudiante. Cada una de ellas está constituida por unas formas específicas de relacionarse con los saberes, con las estrategias de aprendizaje y con las formas de legitimar los conocimientos adquiridos.

En la primera representación, indicada en la tabla 4 con el símbolo R1, identificamos una imagen de sumisión asociada al estudiante, que se caracteriza por la obligación institucional de aprender ( $B$ es obligado a aprender o $A$ evalúa a $B$ ). Puesto que nuestros informantes no perciben este tipo de aprendizaje como significativo, ellos juzgan que el conocimiento se construye por obligación institucional, por ende, los participantes colombianos asocian a esta representación las cualidades dependencia, generalmente del profesor, y desinterés por lo que se aprende, mientras que los participantes franceses asocian el aprendizaje a la inmediatez de la evaluación.

Para los informantes colombianos la representación R1 correspondería a un aprendizaje tradicional que se caracteriza por una obligación de asistencia a una institución educativa para recibir y acumular unos saberes. Esta situación genera un aprendizaje sin objetivos sociales e intelectuales definidos, razón por la cual el núcleo de los encuestados colombianos en R1 se termina simplemente con el bloque: estudiante PLT aprender, o sea hay una ausencia respecto al resultado que produce el aprendizaje. Además, la relación estudiante-profesor es unidireccional y calificada por los encuestados como "dependiente" pues el primero acepta lo que el 
segundo le brinda. En el caso de los informantes franceses, el aprendizaje es poco significativo cuando los alumnos se ven en la obligación de aprender saberes demasiado teóricos que servirán únicamente para ser evaluados por el profesor; estos esfuerzos hechos en vano conducirán a un sentimiento de insatisfacción y al desinterés ya que el estudiante juzga que su aprendizaje solo sirve para legitimarse ante la institución educativa, pero no para ser competente y asegurar su entrada en los sistemas productivos y sociales de su comunidad. De acuerdo con nuestros participantes, el peso de la institución educativa podría convertirse en un obstáculo para el verdadero aprendizaje o incluso podría ser insuficiente razón por la que un verdadero estudiante buscar el "conocimiento fuera de $A$ ".

La valoración negativa de esta representación del estudiante como un sujeto que aprende para legitimar sus conocimientos, exclusivamente en el seno de su institución, constituye nuestro primer punto de diálogo intercultural. Efectivamente los estudiantes colombianos y franceses comparten la imagen del estudiante como un sujeto que se educa con el fin de ser partícipes, de manera inmediata, en la reflexión y construcción de su sociedad; esto justifica la presencia del bloque argumentativo estudiante PLT servir a la nación y representar la nación. Nuestros encuestados consideran que su condición de estudiantes no les debe negar su rol de ciudadanos, por lo que los modelos de enseñanza y las estrategias de aprendizaje significativas deben involucrar al estudiante en la reflexión de su entorno. En consecuencia, una educación intercultural debe constituirse a partir de estrategias de enseñanza y aprendizaje que conviertan a quienes se educan en ciudadanos críticos e informados que participan en la toma de decisiones de la sociedad donde se educan.

En la segunda representación (R2), la imagen del estudiante es más bien asociada a la idea de actor. Prima aquí su voluntad en la decisión de lo que va a aprender y para lo que se va a hacer competente. En esta representación observamos que los verbos de acción dan cuenta de la implicación del alumno en el proceso de aprendizaje, buscar el saber o hacerse competente -nótese que la última expresión verbal está constituida por un verbo pronominal que intensifica la idea de un individuo autónomo en la adquisición de habilidades durante su formación-. De igual manera, las cualidades asociadas al estudiante interesado, aplicado, autónomo refuerzan la idea de que la adquisición de conocimientos y competencias surge principalmente cuando el estudiante aplica sus esfuerzos para la consecución de una meta de aprendizaje. Dicha meta estaría asociada con la necesidad del alumno de hacerse competente y así participar como ciudadano y profesional en la construcción de la sociedad. Aunque en este modelo el estudiante se represente como un ser autónomo, la presencia del profesor permanece, pero como un intermediario que ayuda o guía a 
los alumnos a construir significados y a atribuir sentido a los contenidos que aprenden. Esta representación constituiría el segundo elemento de nuestro diálogo intercultural.

\section{Cierre}

El estudio comparativo de las representaciones del estudiante obtenidas en diccionarios y en el discurso de 25 estudiantes colombianos y 25 franceses, pertenecientes a dos instituciones educativas, demostró que es posible definir esta identidad profesional a partir de ciertas propiedades esenciales que son transversales a nuestras dos comunidades lingüístico-culturales. En esencia, el estudiante se define por su voluntad y esfuerzo para adquirir conocimientos y competencias en el marco de una institución educativa. Este aprendizaje es motivado por dos objetivos: adquirir conocimientos y habilidades para que el sujeto-pensante pueda insertarse en el mundo laboral y socializar como ciudadano. Aunque aprender dependa primordialmente del interés del estudiante, los corpus lingüísticos y discursivos atribuyen al profesor un rol fundamental de mediador que guía y asegura los aprendizajes.

Las representaciones obtenidas a partir del discurso de los informantes colombianos y franceses nos conducen a pensar que una educación internacional significativa se construye a través de la participación del estudiante en intercambio en la interpretación de las realidades locales a las que este pertenece o a las que se va a integrar. En vez de optar por una formación de asimilación y uniformización cultural y académica, el estudiante que se forma en otro país podría educarse en un escenario que le pide aportar una nueva interpretación para la sociedad que lo acoge y que conformaría su nueva realidad local. Esta interpretación se haría a partir de las experiencias y de los saberes que el estudiante ha construido en su comunidad de origen. De igual manera, se esperaría que la formación que sigue el estudiante en otra institución contribuyeran a forjar nuevos horizontes interpretativos de su sociedad. Es decir, la internacionalización de la educación, además de preocuparse por el desarrollo de contenidos y de competencias laborales, podría vincular a los estudiantes en intercambio en la participación de la vida ciudadana como un nuevo espacio de formación humano e intelectual donde se desarrollan competencias transversales de comprensión y comunicación intercultural.

Hoy en día la internacionalización de la educación, y en particular la universitaria, tiende a desarrollarse a partir de una corriente que aboga por el uniculturalismo académico. Dicho modelo se basa en la asimilación académica y cultural, en la cual quienes se educan deben adaptar su identidad de estudiantes a las expectativas y a la cultura académica de 
la institución que los acoge. Así, la internacionalización se caracteriza por la uniformización lingüística que es garantizada en la mayoría de los casos por la hegemonía de la lengua inglesa en el mundo académico y científico. Ello provoca que en varias instituciones se deje de lado el aprendizaje de la lengua local en la medida en que el inglés es la lengua de comunicación dentro de los procesos de enseñanza y aprendizaje. Aun si este modelo de internacionalización sigue siendo atractivo en la medida en que los estudiantes satisfacen sus necesidades de adquisición de ciertas competencias que les permiten insertarse en el mundo laboral, los aprendizajes se pueden percibir como no significativos, puesto que no constituyen un escenario y un elemento para la interpretación de la sociedad que los acoge y muchas veces para la comunidad de donde proviene el estudiante.

La internacionalización de la universidad también se puede concebir desde un modelo de interconstrucción cultural, en el cual las representaciones del aprendizaje y de la enseñanza constituyen la materia prima para la transformación y posible reevaluación de los modelos pedagógicos ya institucionalizados en las universidades que participan en intercambios estudiantiles. La primera etapa para establecer un diálogo intercultural de las prácticas pedagógicas y de aprendizaje puede estar constituida por la observación que el profesor realiza de las prácticas de aprendizaje de los estudiantes en intercambio. Esta observación puede evolucionar en una explicitación de las prácticas de aprendizaje de estos estudiantes. La observación y reflexión alrededor de estas nuevas prácticas enriquecería los modelos de enseñanza y aprendizaje de las universidades que se abren al mundo de la internacionalización.

Con esta investigación no se busca dar pautas sobre cómo deberían construirse las relaciones de interculturalidad dentro y fuera del aula de clase. Se trata más bien de ofrecer una reflexión sobre la multiplicidad de visiones respecto a las identidades y roles del estudiante en dos comunidades lingüístico-culturales, al mismo tiempo que mostramos que hay ciertos rasgos de las representaciones de cada grupo que pueden ser el punto de partida para comprender lo que significa aprender y para qué se aprende. En definitiva, el impacto de los intercambios estudiantiles no reside solo en las diferencias que percibimos en el Otro, sino sobre todo en los elementos comunes que nos permiten establecer un diálogo intercultural $y$, en fin, reconocernos como seres humanos. 


\section{Referencias}

Anscombre, J.-C. (2001). Le rôle du lexique dans la théorie des stéréotypes. Langages, 35(142), 57-76.

Barbier J.-M. (2006). Constructions identitaires et mobilisation des sujets en formations. París: Harmattan.

Barbier, J.-M. y Galatanu, O. (2004). Les savoirs d'action : une mise en mots des compétences ? París: L'Harmattan.

Charaudeau, P. (2001). Langue, discours et identité culturelle. Études de linguistique appliquée, 3-4, 341-348. Recuperado de https://www. cairn.info/revue-ela-2001-3-page-341.htm.

Dervin, F. (2008). Métamorphoses identitaires en situation de mobilité. Finlandia: Universidad de Turku.

Galatanu, O. (2000a). Signification, sens et construction discursive de soi et du monde. En J.-M. Barbier y O. Galatanu (eds.), Signification, Sens, formation. París: PUF.

Galatanu, O. (2000b). Langue, discours et systèmes de valeurs. En E. Suomela-Salmi, (ed.), Jalons: Curiosités linguistiques, n³ (pp. 80-102). Turku: Presse Université de Turku.

Galatanu, O. (2007). Sémantique des "possibles argumentatifs" et axiologisation discursive. En D. Bouchard \& J. Evrard (eds.), Représentation du sens linguistique 2 (pp. 313-325). Louvain-La-Neuve: De Boeck-Duculot.

Galatanu, O. (2009). L'analyse linguistique du corpus discursif. Cahiers du Laboratoire de Recherche sur le Langage, 2, 49-68.

Larousse y Nimmo C. (2014). Le Lexis: Le dictionnaire érudit de la langue française. París: Larousse.

Littré, Beaujean y Pruvost. (2004). Le nouveau Littré (Edition augmentée du Petit Littré). París: Garnier.

Moliner, M. (2007). Diccionario del uso del español (2. edición). Madrid: Gredos.

Real Academia Española (RAE) (2003). Diccionario de la lengua española (22. ${ }^{a}$ edición). Madrid: Espasa.

Rey, A. y Robert P. (2011). Le petit Robert: Dictionnaire alphabétique et analogique de la langue française (Nouvelle édition millésime 2012). Paris: Le Robert.

Ricœur, P. (1985). Temps et récits III, Le temps raconté. París: Editions du Seuil.

Seco, M., Andrés, O. y Ramos, G. (1999). Diccionario del español actual. Madrid: Aguilar.

Trésor Informatisé de la langue Française. Paris: Atilf. Recuperado de http://atilf.atilf.fr/tlf.htm.

Zavalloni, M. (1998). Vers une orientation et une intervention interactive: I'identité comme hipertexte. En L'orientation scolaire et professionnelle, 27, 5-22. 